\title{
Progress in defeating depression
}

\author{
R. G. Priest, E. S. Paykel, Deborah Hart, D. S. Baldwin, Ann Roberts, \\ and Christine Vize
}

The Defeat Depression campaign, conducted by the Royal College of Psychiatrists in association with the Royal College of General Practitioners, is now over half way through its five year course. It is time to consider what we have achieved so far.

The campaign arose out of our concern that even though depression is a treatable disorder, many sufferers do not seem to be getting treatment, or are getting it only after unnecessary delays of months or years. Until recently possibly half of the persons afflicted by depression were not even going to their general practitioners (GPs). Of those that did go, a further $50 \%$ were not diagnosed as suffering from depression (at least at the first interview) (Priest, 1991; Priest, 1994; Wright, 1993).

The problem seemed to be a combination of a stigma prevailing among the general public, and even now imperfect skills in the medical profession in recognising (and to some extent in treating) the illness.

The objectives of the campaign are as follows (Priest, 1991).

(a) For the general public, to enhance awareness of the nature, course and treatment of depressive disorder, to make high risk populations more aware of the existence of depressive illness and its amenability to treatment, to reduce the stigma associated with depression as a mental illness and to encourage people to seek help more readily from primary care and mental health services.

(b) For the medical profession, to publish agreed consensus statements on the recognition and treatment of depressive disorders in general practice, to increase the knowledge of general practitioners and other health care professionals in the recognition and effective treatment of depressive illness, to explore the potential for prevention of depressive illness through earlier recognition of symptoms, to ensure that treatment is maintained for as long as is necessary and to measure the effectiveness of the professional education campaign.

\section{Attitudes of the public}

The Defeat Depression campaign was launched in January 1992. One of our first tasks was to carry out two surveys on public attitudes. Although we believed that there was, in the layman's mind, a stigma associated with depression, we wished to get chapter and verse for this belief and to be more precise about its nature. The first survey was a qualitative one, with researchers interviewing small samples of the general public in groups. The second was a quantitative survey on a stratified sample of 2009 conducted by MORI (Vize \& Priest, 1993).

The qualitative survey suggested that people were disinclined to visit their family doctors with a complaint of depression or an emotional problem, but would be prepared to go with physical symptoms such as insomnia. They thought that drugs, such as benzodiazepine tranquillisers, were used to dull the problem. Counselling was favoured as the most effective and appropriate treatment since it could get to the root of the problem.

The MORI survey confirmed and clarified these attitudes. Over $90 \%$ of people interviewed thought that depressed patients should be offered counselling, while only $16 \%$ felt that they should be given antidepressants. A massive $78 \%$ believed that antidepressants were addictive. Efficacy was attributed to antidepressants by $46 \%$ and to counselling by $85 \%$. Half of the respondents thought that if they went to a GP with depression they would be regarded as unbalanced or neurotic (Vize \& Priest, 1993).

\section{The first consensus statement and medical education}

Two consensus meetings were held in late 1991 (organised by the Scientific Advisory Committee and mainly made up of members of the two 
Colleges). The first was on the diagnosis and recognition of depression. The topics discussed were formulated as questions: What is depression? How common is it in different settings? Why is it missed? What can be done to improve recognition? What are the benefits? Since many GPs have not been taught modern definitions of depression, particularly the concept of major depression, how in practice is it evaluated and distinguished from normality in terms of severity and number of symptoms? The second conference dealt with treatment and covered five further questions: What is the role of antidepressant medication? What should be done to prevent relapse? What is the role of psychosocial management? What is the role of psychological therapies? When is a psychiatric referral appropriate? As far as drug treatment is concerned, one important recommendation was that after remission of symptoms has been achieved the antidepressant should be continued for four to six months to prevent relapse, at a dose close to the original. This applies even to first episode depression in primary care. The value of cognitive therapy was also recognised, and it was pointed out that even if a full course of treatment was not available, some of its principles could be used by doctors with good effect (e.g. diary keeping. self-help tasks, as homework). The agreed consensus conclusions of these two conferences were published in the British Medical Journal as a consensus statement (Paykel \& Priest, 1992), and received considerable attention. Management guidelines based on the consensus statement have been distributed to all GPs in Great Britain and to all consultant psychiatrists in the UK, with the assistance of the Department of Health.

A second pair of consensus conferences on depression in later life, organised by Professor C. Katona and Professor P. Freeling, was held in 1993. A similar balance of psychiatrists and GPs was involved. A consensus statement has been prepared for publication. Topics addressed include frequency of depression in later life; older people who are particularly at risk; differences from depression earlier in adult life; use of screening; reasons for depression being missed; suicide; management strategies; antidepressants; ECT; lithium; psychosocial management; length of treatment; referral for specialist help; outcome.

An educational package entitled Depression from Recognition to Management for primary care trainers has been produced, containing two videotapes, templates for overhead projection transparencies and booklets for trainees which contain the same lists that appear in the transparencies. One of the aims of this package is to improve the interviewing skills of GPs so that the rate of detection of depression is significantly improved.

The educational task is a challenging one. Interviewing skills are increasingly being taught in medical schools, and in particular the value of open-ended questions and perceptive listening are emphasised. This is clearly relevant to patients with psychological problems, particularly when they present in the guise of physical symptoms (as do many patients with depression in primary care probably the majority). However, in order to make the diagnosis of depressive illness, enquiry must be made about specific symptoms, which are not necessarily volunteered spontaneously, and this requires direct (often closed) or even leading questions.

The package is designed to teach the skills needed to carry out these apparently conflicting tasks in an apt manner. The preliminary reaction to the package from primary care trainers has been favourable but further work is required to develop and evaluate it.

Meanwhile, this first video training package which was launched in 1993 has sold out and was recently re-printed.

\section{Counselling depression in primary care}

Depression is essentially a general practice illness. In any one year, GPs will record the diagnosis of depression in $3 \%$ of the population, and it is probable that a similar number of depressed patients will go unrecognised. Only $10 \%$ of depressed patients will be referred to a psychiatrist, and only $1 \%$ will be admitted to hospital. It falls to the GP and members of the primary care team. therefore, to recognise and manage the majority of people suffering from depressive illness.

Antidepressant drugs are effective in treating depressive disorders which reach the criteria for major depression, or fall slightly short of this threshold. However, these drugs are ineffective in the treatment of very mild states of depression and they should not be used as the sole approach to the management of a depressed patient. Psychological interventions, 
such as counselling, provide a complementary approach to antidepressant drugs and may offer some protection against relapse and recurrence.

In October 1994 the campaign launched a new video training package designed to complement the first by offering guidance and training on how to counsel depressed patients in general practice.

Counselling Depression in General Practice was developed by Dr Linda Gask, a consultant psychiatrist from the University of Manchester, who specialises in the development of mental health training materials; Dr Tim Usherwood, Senior Lecturer in General Practice at the University of Sheffield with a special interest in depression; Professor Jan Scott, Professor of Community Psychiatry at the University of Newcastle upon Tyne, a leading expert in cognitive behavioural therapy; and Dr Sally Standart, Lecturer in Primary Health Care, University of Newcastle upon Tyne.

The training package consists of a videotape, templates for overhead projection transparencies, background reading material for those attending the course and a patient booklet. The materials are designed for a half or one day workshop on counselling depression in primary care.

\section{Public education in depression}

Initial activities of the Defeat Depression campaign had been directed at the medical profession. Although our colleagues, particularly those in primary care, had warmly supported the campaign, there was clearly a potential danger. If we had been successful in encouraging large numbers of patients to go along to doctors with their so far untreated depression, this might have been rather overwhelming for the primary care practices. We took the view that it was important to bring the state of the art knowledge on the management and treatment of depression to the notice of GPs before we put all our energies into changing the attitudes of the public.

One of the most important objectives of the campaign, however, is to reduce the stigma associated with depression and encourage people to seek help more readily. Three leaflets for the general public have now been produced on Depression. Depression in the Elderly and Depression in the Workplace. A new leaflet on Postnatal Depression was recently launched at a joint conference between the campaign, the College and the Marcé Society. Over 4 million leaflets altogether have been distributed up till now!

The campaign also has a high media profile, organising press briefings to launch all the new initiatives and proactively encouraging coverage in both medical and paramedical journals, radio, TV and newspapers, both at a regional and national level.

In March 1994, we held the widely publicised Defeat Depression Action Week. During the week there was a series of media briefings in London hosted by the Royal College of Psychiatrists, the Royal College of General Practitioners, MIND and the Health Visitors Association. Further events were initiated during the week throughout the country. There was a Fun Run in Hyde Park (with 250 people entering), a large conference on depression in Leeds, and some members of the College even abseiled down the front of Manchester City Hall. Clare Rayner spoke about both her and her husband's 'black dog' in a very moving address. The Action Week had been coordinated by a national network of psychiatrists, GPs, sufferers, nurses, health visitors and many others and we can attribute its great success to their efforts.

A Defeat Depression Action Day took place on 12 April 1995 which was preceded by a Fun Run in Battersea Park on Sunday, 9 April 1995.

Shortly before the Action Week we published a very readable book on depression for the lay person written by Professor Brice Pitt and illustrated by the well known cartoonist Mel Calman. It was a great sadness when Mel died two weeks after the book came out.

An audio cassette entitled Coping with Depression was launched last year which is designed to bring coping skdlls to people suffering from depression. The tape describes how to alleviate symptoms of depression using simple but effective self-help techniques and offers a programme of basic cognitive therapy skills.

Factsheets on depression in five ethnic minority languages (Chinese, Hindi, Gujarah. Bengali and Punjabi) were recently launched by the campaign and will hopefully raise awareness of depression within ethnic communities.

Many new and exciting initiatives are planned for the remainder of the campaign both for the general public but also for health care professionals. 


\section{The Scientific Advisory Committee}

The overall national direction of the campaign is set by the Management Committee (see membership list at end of article). Regional activities are organised by members of both Colleges.

The Scientific Advisory Committee of the Defeat Depression campaign is the companion committee to the Management Committee. The Committee, which was established at the inception of the campaign, undertakes scientific activities related to depression and to the aims of the campaign, and advises the campaign on scientific issues. The principal activities which the Committee has undertaken are set out below.

The first activities of the Scientific Committee were the Consensus Meetings mentioned earlier. In addition it is active particularly in evaluating the campaign and setting up scientific conferences. These two topics will now be described.

\section{Evaluation of the campaign}

The campaign is based partly on an educational campaign for general practitioners which took place on the Swedish island of Gotland in 1983 and 1984. In an evaluation of that campaign (Rutz et al, 1990; 1992) rates of admission, prescribing patterns and suicide rates were monitored before, during and after the saturation educational programme (Rutz et al, 1992). Hospital admission and sick leave for depression were lowered, prescription of antidepressants was increased and prescription of tranquillisers decreased. The suicide rate was lower, but the island was really too small in population to test this effect. Unfortunately three years later these changes had reverted back rather than persisting, except for the increase in antidepressant use. In the Gotland study it was possible to validate findings by making comparisons with the Swedish mainland. Evaluating a national campaign like the Defeat Depression campaign is difficult: only before-after evaluation is possible, but it may be confounded by other changes taking place nationally, such as the development of fund-holding in general practice, and particularly, the welcome highlighting of prevention of suicide by its inclusion as a Health of the Nation target.

It is hoped to undertake the following evaluations:

(a) Attitudes of general public. A survey of attitudes to depression in the general public was carried out by MORI at the beginning of the campaign. This was repeated early in 1995 (and will be reported in a later publication).

(b) Recognised morbidity. Data on recognised morbidity in selected practices are collected regularly by the Royal College of General Practitioners Research Unit in Birmingham. It is hoped that this can be analysed to determine consulting rates for depression and for other disorders which might reflect unrecognised depression, over the period 1985-1994 and examined annually. This could be supplemented by data from the Fourth National Morbidity Survey (1991-92). If the campaign is effective, rates of recognised depression should rise, and rates of alternative diagnoses reflecting unrecognised depression should fall.

(c) Prescribing rates. Using national prescription data, it is proposed to examine prescriptions of antidepressants over the 1980s and 1990s. It will be necessary to examine different classes of antidepressants, and desirable if possible to determine whether quantities prescribed have changed, since data avallable are for numbers of prescriptions rather than amounts prescribed. Estimates of changes in dosage prescribed and length of antidepressant courses will also be attempted.

(d) Impact on general practitioners. There are many educational activities for GPs and it is not necessarily the case that any changes in GP behaviour which are demonstrated will be the result of the Defeat Depression campaign. It is necessary to audit the educational activities to determine their appropriateness and effectiveness in reaching GPs. Funding has been obtained from the Department of Health for this purpose. It is intended to devise a questionnaire and distribute it to GPs to assess receipt of educational activity of various kinds and origins by GPs, awareness and use of the campaign, the consensus statements, depression guidelines and card, other educational materials and the new GP mental health educational network, factors used by GPs to facilitate recognition of depression, details of usual GP treatment practices for 
depression. The questionnaire will be distributed through the Royal College of General Practitioners to a sample of its members, and by an alternative route to a sample of non-members, with active telephone follow up to achieve good rates of return.

\section{Scientific conferences}

Two meetings were held in late 1994 and one early in 1995, as scientific conferences, rather than consensus conferences. The aim was to bring together and make more widely known existing research and information, rather than to formulate guidelines. The first conference, held on 18 November, was on Depression in a Multi-Ethnic Society. Dr D. Bhugra assisted in the organisation. The aim was to bring together existing studies on depression in various ethnic groups in Britain, particularly Afro-Caribbean and Asians, a subject which hitherto had not received sufficient attention.

The second scientific conference was on 8 December and was organised jointly with the Marcé Society, with the title 'Defeating Post Natal Depression'. It dealt with a number of important aspects including frequency of depression, screening, impact on children, and service needs. There has been a large body of research on these topics in the last four years.

The first activity in 1995 was a conference on Depression in Children and Adolescents. There has been much research on this subject. While this is well known to child psychiatrists it has been much less accessible to GPs. This meeting provided one of the first opportunities for an important sharing of experience on this topic between child psychiatry and general practice.

A further programme of activities is planned for later in 1995 and 1996.

\section{References}

PaYkel E. S. \& PRIEst, R. G. (1992) Recognition and management of depression in general practice: consensus statement. British Medical Journal. 305. 1998-1202.

PRIEST. R. G. (1991) A new initiative on depression. Brttish Journal of General Practice, 41, 487.

- (1994) Improving the management and knowledge of depression (editorial). British Joumal of Psychiatry, 164. 285-287.
RUTZ, W., VON KNORRING, I. \& WALNDER, J. (1989) Frequency of suicide on Gotland after systematic postgraduate education of general practitioners. Acta Psychiatrica Scandinavica, 80, 151-154.

-. - . - \& WISTEDT, B. (1990) Effect of an educational program for general practitioners on Gotland on the pattern of prescription of psychotropic drugs. Acta Psychiatrica Scandinavica, 82, 399-403.

- . - \& - (1992) Long-term effects of an educational program for general practitioners given by the Swedish Committee for the Prevention and Treatment of Depression. Acta Psychiatrica Scandinavica, 86, 83-88.

WRIGHT. A. F. (1993) Recognition and Management in General Practice. London: Royal College of General Practitioners.

VIZE, C. M. \& PRIEST, R. G. (1993) Defeat Depression campaign: Attitudes towards depression. Psychiatric Bulletin, 17. 573-574.

R. G. Priest, E. S. Paykel, Deborah Hart, D. S. Baldwin, Ann Roberts, and Christine Vize, on behalf of the Defeat Depression Campaign

Reprint requests to: Professor R. G. Priest, Head, Department of Psychiatry. Paterson Wing Building, 20 South Wharf Road, London W2 1PD

\section{Appendix}

\section{Membership of the Management Committee}

Professor R. G. Priest (Chairman), Dr Andre Tylee, Liz Armstrong, Vanessa Cameron, Chris Gear, Deborah Hart, Dr Lotte Newman, Elleen Fursland, Doris Kempe, Roland C. Powell, Professor E. S. Paykel, Dr R. Williams, Dr Linda Gask, Dr D. Baldwin, Jill Phillipson, Professor A. Clare, Dr D. Kelly, Dr P. McKeon, Mrs J. Kilshaw, Brian Rhodes, Dr A. C. Cohen, Ms Jean James, Dr A. Roberts, Dr Richard Maxwell, Professor Chris Brewin, Dr Frank Smith, Dr N. Anderson, Professor Sheila Hollins.

\section{Membership of the Scientific Committee}

Professor E. S. Paykel (Chairman), Professor P. Freeling, Professor D. Goldberg, Deborah Hart, Professor S. A. Montgomery, Professor J. Scott, Dr Linda Gask, Dr I. Pullen, Dr A. Tylee, Dr A. Wright. 